\title{
Pudendal Nerve Latency Time in Normal Women via Intravaginal Stimulation
}

\author{
Geraldo A. Cavalcanti, Gilberto M. Manzano, Lydia M. Giuliano, Joao A. Nobrega, Miguel \\ Srougi, Homero Bruschini
}

Departments of Urology and Neurology, Federal University of Sao Paulo, UNIFESP, Paulista

School of Medicine, Sao Paulo, SP, Brazil

\begin{abstract}
Introduction \& Objectives: Studies of motor conduction for the efferent functional assessment of the pudendal nerve in women with pelvic dysfunctions have been conducted through researching distal motor latency times. The transrectal approach has been the classic approach for this electrophysiological examination. The objective of the present study is to verify the viability of the transvaginal approach in performing the exam, to establish normal values for this method and to analyze the influence of age, stature and parity in the latency value of normal women.

Materials and Methods: A total of 23 volunteers without genitourinary pathologies participated in this study. In each, pudendal motor latency was investigated through the transvaginal approach, which was chosen due to patient's higher tolerance levels.

Results: The motor response represented by registering the M-wave was obtained in all volunteers on the right side (100\%) and in 13 volunteers on the left side (56.5\%). The mean motor latency obtained in the right and left was respectively: 1.99 \pm 0.41 and $1.92 \pm 0.48$ milliseconds $(\mathrm{ms})$. There was no difference between the sides $(\mathrm{p}=0.66)$. Latency did not correlate with age, stature or obstetric history. The results obtained in the present study were in agreement with those found by other researchers using the transrectal approach.

Conclusion: The vaginal approach represents an alternative for pudendal nerve distal motor latency time, with similar results to those achieved through the transrectal approach. Normative values obtained herein might serve as a comparative basis for subsequent physiopathological studies.
\end{abstract}

Key words: electrodiagnosis; pelvic floor; urinary incontinence; perineum; neurophysiology

Int Braz, J Urol. 2006; 32: 705-12

\section{INTRODUCTION}

Somatic innervation of the female pelvic floor is basically represented by the pudendal nerve. The integrity of this nerve is important for the functioning of the skeletal musculature of this region, part of the mechanism that sustains pelvic structures and for anal and urethral sphincteric activity (1). This nerve is characterized by presenting sensitive and motor fibers derived from the medullar segments $\mathrm{S}_{2}-$ $\mathrm{S}_{4}$. Its inferior rectal and perineal ramifications play an important role in external anal and urethra sphincter innervations respectively (2).

Efferent functional neurological analysis is performed through measurement of motor conduction speed. This method requires access to 2 separate points of the same nerve for stimulation and registration, making its application on the pelvic floor difficult (3). 
Thus, research on distal motor latency described by Kiff \& Swash (4) became an alternative in the propedeutic of abnormalities of pudendal nerve motor function. The advantage lies in the need to stimulate only one point of the nerve. Registration can be made in the anal sphincteric musculature corresponding to the compound muscular potential of action or M-wave. These researchers also developed the St. Mark's pudendal electrode - a name given in honor of the institution where they worked (St. Mark's Hospital, London, UK). This is a self-adhesive electrode placed on the researcher's index finger at a fixed distance of $3 \mathrm{~cm}$ with bipolar electrodes for stimulation and registration places at the tip and base of the finger respectively (Figure-1). This method is used to investigate lesions of the pudendal nerve associated with dysfunctions in the pelvic floor. Patients with a previous history of obstetric rupture of the anal sphincter presented a higher risk of fecal incontinence when pudendal motor latency was higher than 2 milliseconds (ms) (5). A study in nulliparous patients and in the puerperium showed an extension of latency in the latter persisting for 5 years after vaginal delivery (6). A similar finding was found in women with stress urinary incontinence and concomitant genital prolapse (7). All these studies were conducted through stimulation and transrectal registration. A single previous study comparing the transrectal and transvaginal stimulation routes in the same normal volunteers showed the same findings (8). The present consensus suggests that the transvaginal approach is effective and useful (9), and it has the advantage of allowing greater tolerability by women due to their familiarization with regular gynecological exams.

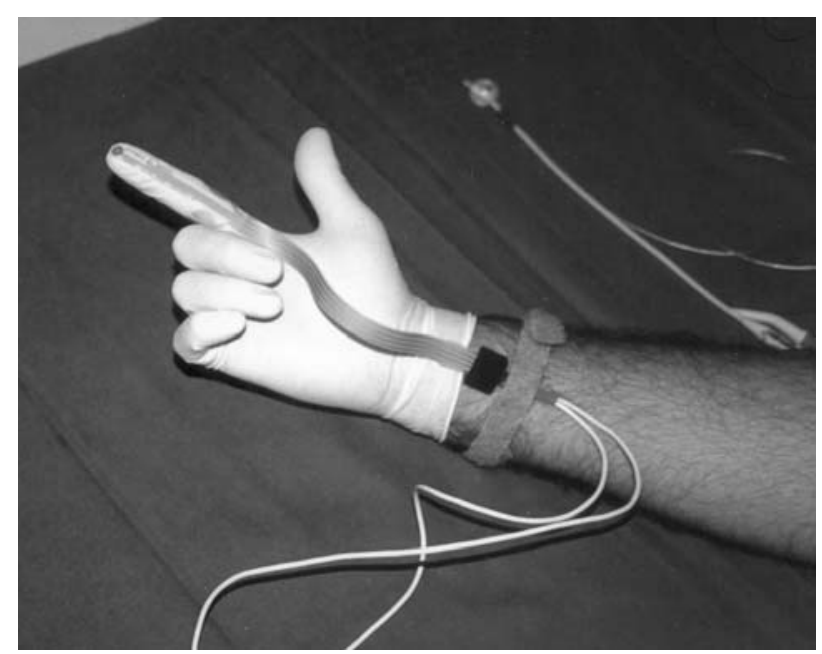

Figure 1 - St. Mark's pudendal electrode stands out in the uroneurophysiology lab. Electrode of stimulation and registration sites, respectively, at the tip and base of the index finger. A distance of $3 \mathrm{~cm}$ separates the registration electrodes from the stimulation cathode.

\section{MATERIALS AND METHODS}

Following approval by the institution's Ethics Committee, a prospective study was performed on 23 normal volunteers. Their characteristics are described in Table-1. Women without significant genitourinary alterations were included, providing no previous history of extensive pelvic and vaginal surgery (including women who had already undergone cesareans or unilateral adnexal surgery), diabetes mellitus, renal insufficiency, alcoholism, hyperthyroidism, present and previous neurological alterations, interstitial cystitis, present urinary infection, voiding dysfunctions, pregnancy or use of a cardiac pacemaker.

Table 1 - Characteristics of the sample in relation to age, corporeal weight, stature and parity (mean \pm standard deviation).

\begin{tabular}{lcccc}
\hline & & & \multicolumn{2}{c}{ Parity } \\
& Age (years) & Stature (cm) & Vaginal Delivery & Total Parity \\
\hline Mean & $34.8 \pm 13.7$ & $159 \pm 7$ & $1.23 \pm 1.01$ & $1.69 \pm 0.85$ \\
nterval & $18-74$ & $140-160$ & $0-3$ & $0-3$ \\
Number of Cases & 23 & 23 & 14 & 24 \\
\hline
\end{tabular}


Four channel Nihon-Kohden electroneuromyography equipment, model Neuropack sigma $(\Sigma)$, was used to perform the examination.

The study was conducted with the volunteer in the lithotomy position. The St. Mark's pudendal electrode (Medtronic Functional Diagnostics A/S, Skovlunde, Denmark, model 13L4401) was attached to the researcher's index finger (Figure-1). In the 14 initial volunteers, the bilateral research was performed only with the right hand of a right-handed researcher. In the last 9 patients, we used the index finger of each hand for the corresponding sides. The identification of the stimulation position was determined in each case, moving the electrode from the tip of the finger until a response with maximum amplitude be reached, using the ischial tuberosity as reference. Stimulation for a duration of 0.2 milliseconds (ms) was performed, and the intensity was increased until reaching the supramaximal response (above which intensity variations do not promote amplitude alterations in the bulbocavernosus muscle). Answers were registered using filters of between $20 \mathrm{Hertz}(\mathrm{Hz})$ and 10 Kilohertz $(\mathrm{KHz})$ for low and high frequency, respectively. We started from an initial sensitivity of 50 microvolts per division ( $\mu \mathrm{V} / \mathrm{div})$ and adjusted it as necessary. We used a base time of $50 \mathrm{~ms}(5 \mathrm{~ms} / \mathrm{div})$. The value of the latency was determined in the moment of starting the muscular depolarization wave deflection or wave -M began.

To compare both side latencies, the t-Student test was used for paired samples. The correlation between the latency value with the age and stature of the volunteers was calculated through Pearson's $r$ coefficient. The same analysis was performed in relation to obstetric history (parity and number of vaginal deliveries) by using the Spearman's $r$ coefficient. For all statistical analysis, a 5\% significance level (p $=0.05$ ) was adopted.

\section{RESULTS}

The exam was well tolerated by the volunteers, who did not report any alterations or discomfort that persisted after its conduction. Registrations of both sides presented the M-wave of the same sig- nal when obtained with the same hand, and inverse signals when each side was approached by fingers from opposite hands (Figure-2). In performing the exam, the M-wave was obtained in all 14 cases on the right side and in $8(57.1 \%)$ on the left side when the same hands were used for both sides. In the last 9 patients, the M-wave was obtained in all volunteers on the right side and in $5(55.6 \%)$ on the left side when fingers of each hand were used for the corresponding sides.

Mean latency time obtained on the right and left sides was, respectively, $1.99 \pm 0.41(1.00-2.40)$ and $1.92 \pm 0.48(1.00-2.60)$ milliseconds (ms). There was no difference between latency values obtained on both sides $(p=0.66)$. There was no correlation of the motor latency of each side with age, stature and obstetric history (Table-2).

The average of the latencies obtained was compared to the values described in the literature for the transrectal approach. The results are showed as floating bars, and the distance between the lateral extremities represents the values of the arithmetic mean of each study added and subtracted from 2 corresponding standard errors. The findings of the present study are in agreement with previously published data (Figure-3).

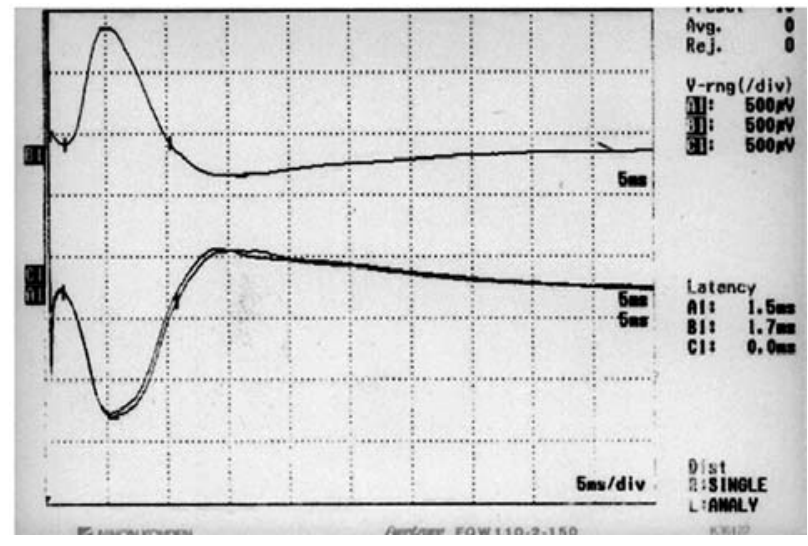

Figure 2 - Registrations of the M-wave. Superior and inferior traces were obtained, respectively on the right and left. They present inverted signals due to the opposed functions performed by the bipolar registration electrodes (active and reference) when we utilize each hand on its corresponding side. 
Table 2 - Correlation between the latency value on each side, the general characteristics, such as age (years), stature (cm), parity (number of deliveries) and the number of vaginal deliveries.

\begin{tabular}{lcccccccc}
\hline & \multicolumn{2}{c}{ Age** } & \multicolumn{2}{c}{ Stature** } & \multicolumn{2}{c}{ Parity* } & \multicolumn{2}{c}{ Vaginal Delivery* } \\
& $\mathbf{r}$ & $\mathbf{p}$ Value & $\mathbf{r}$ & $\mathbf{p}$ Value & r & p Value & r & p Value \\
\hline Right distal motor latency & 0.11 & 0.60 & 0.18 & 0.43 & 0.22 & 0.30 & 0.09 & 0.68 \\
Left distal motor latency & 0.26 & 0.37 & 0.06 & 0.85 & 0.17 & 0.58 & 0.07 & 0.81 \\
\hline
\end{tabular}

* Spearman's $r$ ** Pearson's $r$

\section{COMMENTS}

The present study aimed to establish the applicability of the vaginal approach for the research of pudendal nerve distal motor latency times in normal women. The results achieved were compared with those obtained in other studies through the rectal approach. As well, an analysis was made of the impact

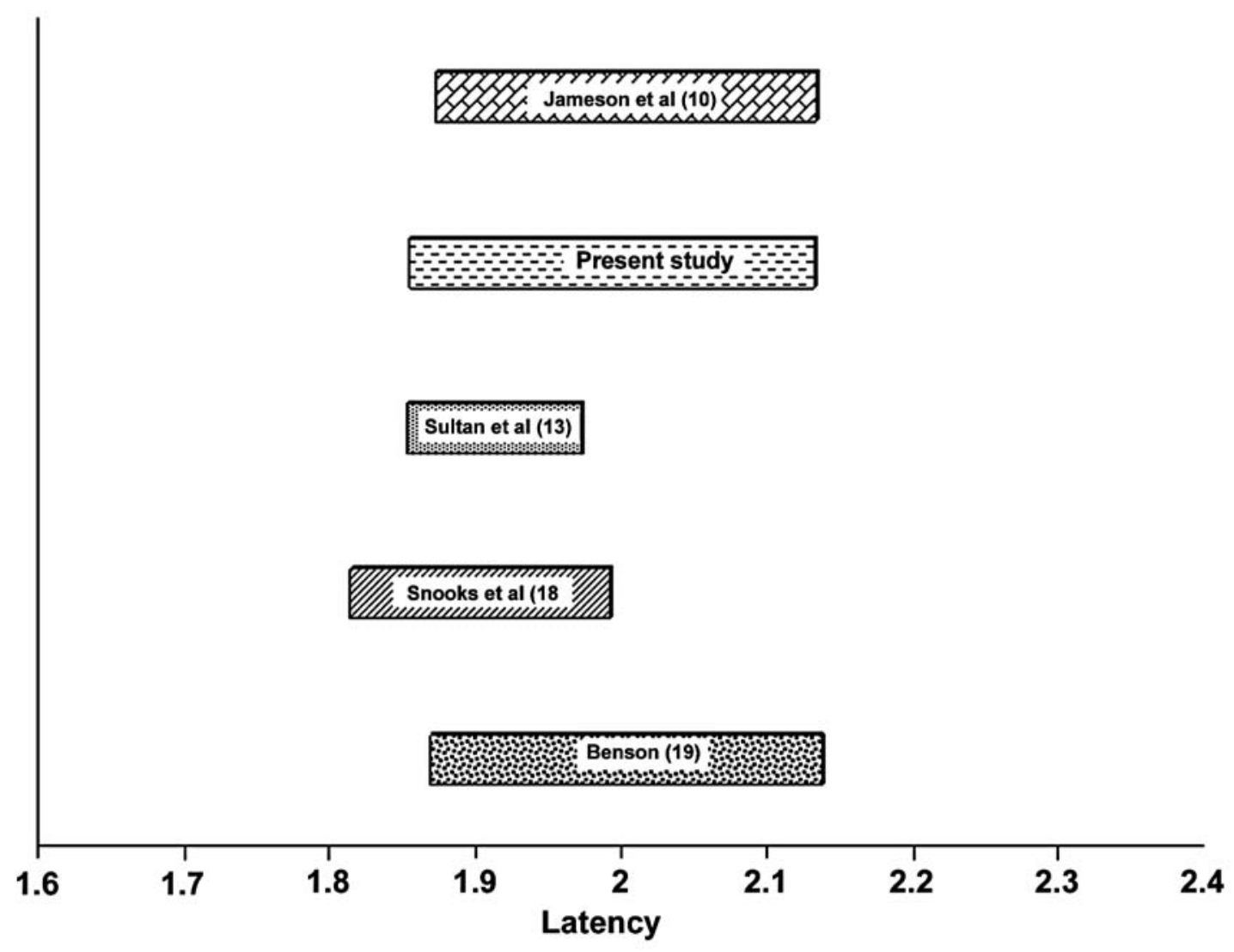

Figure 3 - Pudendal nerve distal motor latency value, corresponding to the arithmetic mean added and subtracted of 2 standard errors in the present study and in comparable literature studies. Ref. $10=51$ women via transrectal approach; ref. $13=57$ women via transrectal approach; ref. $18=20$ women via transrectal approach; ref $19=20$ women via transrectal approach. 
of physiological factors, such as age, stature and parity. Despite potential advantages in some aspects utilizing needle EMG, this comparison was not our objective. The St. Mark's electrode was incorporated for clinical studies due to the facility and trustworthiness of its results and its intravaginal use aims at making it even more practical and tolerable.

The sample size of 23 patients in our study corresponded to the values of the studies utilized for comparison of viability found in the literature. They describe a universal difficulty in obtaining normal volunteers for studies of this nature, which is a probable reason for the lack of assessments in larger populations. The definition of the sample through well defined inclusion and exclusion criteria allowed the determination of values of this electrophysiological exam in a group consisting of women of different ages and obstetric histories, even though presenting no urogenital alterations.

We could not find differences regarding age and corporeal stature in pudendal motor conduction. There is no consensus in the literature regarding the interference of these factors. Jameson et al. (10) have described an extension of pudendal nerve distal motor latency that comes with aging - both in men and women without anorectal alterations. The same behavior in men suggest that other variables such as menopause, potentially related with age, did not interfere in the value of latency in women (11). Similar results were also observed when groups of men and women below 50 years of age were compared (12). However, other researchers did not confirm the influence of age and stature in motor latency using the transrectal approach $(13,14)$. The present work corroborates the absence of such differences, demonstrating that there are no electrophysiological alterations with aging and stature. There is no description in the literature of transvaginal studies similar to this.

Consequences of vaginal delivery and parity in the neurological integrity of the pelvic floor have been a reason for interest and studies. Alterations in pudendal motor latency could already be observed after delivery both in primiparous and multiparous women (13). It is probable that vaginal delivery occurrences can cause transitory neurogenic alterations in the pelvic musculature. However, since vaginal deliveries have not occurred recently, immediate repercussions were not found. According to Wall (15), other associated factors such as the use of forceps, extended expulsive periods during labor, significant perineal ruptures and fetal macrosomia seem to be necessary so that the compromise of pudendal innervations is permanent with definitive abnormalities in neurophysiologic tests and clinical repercussion in the inferior and genital urinary tract.

The utilization of the St. Mark's pudendal electrode for stimulation and registration of pudendal nerve distal motor latency has shown to be effective in obtaining a clean and distinctive answer, which favors standardizing the method. Since it is a study of conduction speed, it assesses only the faster conduction nervous fibers, and thus it is not a good indicator for muscular denervation (16). The amplitude of the answer theoretically reflects the number of excitable motor units and would be a more adequate parameter than latency to identify peripheral neurological lesions. However, its variability with technical and biological factors makes its practical use difficult (10). We should also bear in mind that even though there is a delay in nervous conduction, it is improbable that a pathological effect that would affect the nerve would be sufficient to instigate an increase in the latency value in $1 \mathrm{~ms}$, and that this would be able to influence the time of the reflex answer of motor units (3).

However, contrary to what occurs in pathologies of members, generally when the main nerve trunk is involved neurogenic lesions in the pelvic floor are preferably localized in the distal portion next to the muscle (16). This aspect permits that, despite the limitations of motor conduction conventional studies, pudendal nerve distal motor latency time can detect abnormalities in perineal terminal innervations.

The majority of the authors have approached the pudendal nerve transrectally. The anal sphincter represents a muscular structure suitable as a registration site due both to its external and distal to stimulation, as well as the sufficient quantity of muscle fibers for obtaining an adequate response. Differently from the classic approach, the present study used the transvaginal approach for stimulation and registration, since this approach offers better acceptance and 
comfort for the woman, who is familiar to periodic gynecological exams. Stimulation and registration could be performed in an efficient way on the right side (using the right hand of a right-handed researcher). However, registration on the left side was not obtained consistently in a significant number of cases (43.5\%), as well as the need for a higher intensity of stimulation to obtain a supramaximal registration. The obtainment of a response on the left side was insufficient, both with the efforts on both sides with the same hand and with corresponding hands. Difficulties in positioning the registration electrodes in contact with the bulbocavernosus muscle during the research conducted on the left side seems to be the most probable cause of the differences in findings. This means that in left-handed observers the tendency could be reversed. According to Lefaucheur et al. (12), artifacts and signal distortions could occur with the introduction of the finger and attempt to adequately locate the stimulation point. The research of the pudendal motor latency time with the index fingers of both hands caused different signal registrations due to the opposing function performed by bipolar registration electrodes (active and reference).

The latency value did not present any difference between both sides. This was a different result from other researchers that have identified a tendency in obtaining more prolonged left pudendal latency (12). The bilateral approach, even though recommended for the identification of unilateral neuropathies with possible clinical relevance (17), is limited in this method due to the irregularity in obtaining registration on both sides in normal volunteers.

The findings in the present study agree with the results reported in the literature concerning the latencies obtained through the transrectal approach in normal women $(10,13,18,19)$. This suggests that, in clinical practice, the values obtained can be interpreted independently from the approach used and represent pudendal nerve distal motor conduction since the anal sphincter and the bulbocavernosus muscle are supplied by fibers of similar diameter and the distance between the site of stimulation and registration do not change a fact that is confirmed by the observations of Tetzschner et al. (8). For the same reason, the results shall present variations in relation to gender.
This examination can represent a favorable beginning of a more encompassing study to verify the neurological integrity of the pelvic floor involving other electrophysiological methods, such as motor conduction studies, function and sensitive conduction (research of electric limits and evoked potentials) and research of sacral reflexes (20), making the investigation broader and more precise.

This study allowed familiarization with the neurophysiologic technique described, and correlates the results with some important variables. Our findings in volunteers without urinary symptoms add up to the few number of cases existing on normal values in asymptomatic people, allowing future comparison with patients that present voiding dysfunctions.

\section{CONCLUSIONS}

The vaginal approach has proved to be an alternative to the classical transrectal approach for the evaluation of pudendal nerve distal motor latency time, by using the St. Mark's electrode. Aging, stature and parity did not interfere in the latency value. The values of normality obtained herein for this method might serve as a comparative basis for subsequent physiopathological studies.

\section{ACKNOWLEDGEMENTS}

Research partially financed by FAPESP (State of São Paulo Research Foundation), process \#99/ 11546-5.

\section{CONFLICT OF INTEREST}

None declared.

\section{REFERENCES}

1. Thind P, Lose G: The effect of bilateral pudendal blockade on the adjunctive urethral closure forces in healthy females. Scand J Urol Nephrol. 1994; 28: 249-55. 
2. Juenemann KP, Lue TF, Schmidt RA, Tanagho EA: Clinical significance of sacral and pudendal nerve anatomy. J Urol. 1988; 139: 74-80.

3. Vodusek DB: Evoked potential testing. Urol Clin North Am. 1996; 23: 427-46.

4. Kiff ES, Swash M: Slowed conduction in the pudendal nerves in idiopathic (neurogenic) fecal incontinence. Br J Surg. 1984; 71: 614-6.

5. Tetzschner T, Sorensen M, Lose G, Christiansen J: Anal and urinary incontinence in women with obstetric anal sphincter rupture. Br J Obstet Gynaecol. 1996; 103: 1034-40.

6. Snooks SJ, Swash M, Mathers SE, Henry MM: Effect of vaginal delivery on the pelvic floor: a 5-year follow-up. Br J Surg. 1990; 77: 1358-60.

7. Smith AR, Hosker GL, Warrell DW: The role of pudendal nerve damage in the aetiology of genuine stress incontinence in women. Br J Obstet Gynaecol. 1989; 96: 29-32.

8. Tetzschner T, Sorensen M, Lose G, Christiansen J: Vaginal pudendal nerve stimulation: a new technique for assessment of pudendal nerve terminal motor latency. Acta Obstet Gynecol Scand. 1997; 76: 2949.

9. Vodusek DB, Amarenco G, Batra A, Benson T, Bharucha AE, Podnar S, et al.: Clinical Neurophysiology. In: Abrams P, Cardozo L, Khoury S, Wein A (eds.), Incontinence. 3rd International Consultation on Incontinence. 2005; pp. 675-706.

10. Jameson JS, Chia YW, Kamm MA, Speakman CT, Chye YH, Henry MM: Effect of age, sex and parity on anorectal function. Br J Surg. 1994; 81: 1689-92.
11. Laurberg S, Swash M: Effects of aging on the anorectal sphincters and their innervation. Dis Colon Rectum. 1989; 32: 737-42.

12. Lefaucheur J, Yiou R, Thomas C: Pudendal nerve terminal motor latency: age effects and technical considerations. Clin Neurophysiol. 2001; 112: 472-6.

13. Sultan AH, Kamm MA, Hudson CN: Pudendal nerve damage during labour: prospective study before and after childbirth. Br J Obstet Gynaecol. 1994; 101: 22-8.

14. Barrett JA, Brocklehurst JC, Kiff ES, Ferguson G, Faragher EB: Anal function in geriatric patients with faecal incontinence. Gut. 1989; 30: 1244-51.

15. Wall LL: The muscles of the pelvic floor. Clin Obstet Gynecol. 1993; 36: 910-25.

16. Fowler CJ: Pelvic floor neurophysiology. Methods in clinical neurophysiology. Dantec, Copenhagen. 1991; p. 1-24.

17. Sangwan YP, Coller JA, Barrett RC, Roberts PL, Murray JJ, Rusin L, et al.: Unilateral pudendal neuropathy. Impact on outcome of anal sphincter repair. Dis Colon Rectum. 1996; 39: 686-9.

18. Snooks SJ, Henry MM, Swash M: Faecal incontinence due to external anal sphincter division in childbirth is associated with damage to the innervation of the pelvic floor musculature: a double pathology. Br J Obstet Gynaecol. 1985; 92: 824-8.

19. Benson JT: Pelvic floor neurophysiology. In: American Association of Electrodiagnostic Medicine, Workshop. 1998.

20. Cavalcanti GA, Manzano GM, Bruschini H, Giuliano LM, Srougi M, Nobrega JA: Pudendo-anal reflex in normal women. Arq Neuropsiquiatr. 2004; 62: 839-43.

Accepted after revision:

April 5, 2006

\footnotetext{
Correspondence address:

Dr. Homero Bruschini

Rua Barata Ribeiro, 414 / 35

São Paulo, SP, 01308-000, Brazil

Fax: + 5511 3218-8283.

E-mail: bruschini@uol.com.br
} 


\title{
EDITORIAL COMMENT
}

Pudendal nerve distal motor latency time registration appeared as a promising alternative in the neurofunctional assessment of the pelvic floor, since the measurement of the speed of nervous motor conduction is not applicable in this region. The development of the St. Mark's electrode has made the application of this neurophysiological test easier.

In most centers, the research of pudendal distal motor latency time is made through the transrectal approach. In the present study, the authors prospectively assess the use of the vaginal approach for this neurophysical registration in normal women. It is worth mentioning the difficulty of conducting a study in normal patients. Yet despite the justifications presented by the researchers regarding the discomfort reported by the patients when undergoing the transrectal approach, both approaches (vaginal and rectal) have not been compared in the same patient, revealing a point of uncertainty about the method and, as a result, in analysis of the results. This demonstrates the importance of demonstrating the viability of executing pudendal nerve distal motor latency research through the vaginal approach, as well as its normal reference values.

There are a considerable number of publications establishing pudendal distal motor latency val- ues in patients with stress urinary incontinence, pelvic prolapse and its variations by age, biotype and previous surgeries $(1,2)$. However, there is still no consensus regarding the validity of this assessment value since there is a great variation in its specificity, sensibility and reproducibility. An example of this is the decision of the American Gastroenterological Association recommending the use of the pudendal distal motor latency registration in the assessment of people with fecal incontinence (3). Its practical application in female urology and other voiding dysfunctions lacks complementary studies.

\section{REFERENCES}

1. Benson JT, McClellan E: The effect of vaginal dissection on the pudendal nerve. Obstet Gynecol. 1993; 82: 387-9.

2. Smith AR, Hosker GL, Warrell DW: The role of pudendal nerve damage in the aetiology of genuine stress incontinence in women. Br J Obstet Gynaecol. 1989; 96: 29-32.

3. Barnett JL, Hasler WL, Camilleri M: American Gastroenterological Association medical position statement on anorectal testing techniques. American Gastroenterological Association. Gastroenterology. 1999; 116: 732-60.

\author{
Dr. Jose Carlos Truzzi \\ Urology Department \\ University of Santo Amaro, UNISA \\ São Paulo, SP, Brazil \\ E-mail: jctruzzi@hotmail.com
}

